\title{
Technics Lifeless and Technics Alive: Activity Without and With Content
}

ANDREW MURPHIE

Never have we had so many means, but, to our aggrieved shame, never have we had so few projects either. The gap between what we could do and what we in fact do with them characterizes our time of omnipotent impotence.

- Michel Serres

How did so much of contemporary technics become so disappointing, so deadening? How is technics being thought, and worked with, to enliven? What different assemblages and principles are involved? This chapter begins in sympathy with Michel Serres' "aggrieved shame" $(2019,43)$. I argue that a series of Pavlovist variations on powerlessness still inhabits contemporary technics; then suggest principles of escape towards other kinds of relations between technics and worlds. These relations affirm mutual care as well as mutual powers. They would be immanently attentive to the complexity and variability of the world as event.

In this chapter, the term "technics" indicates an ecology that goes beyond technologies. Indeed, the term usually suggests the coming together of technologies with techniques and technical systems. Yet technics is inconceivable without also considering that which is drawn into, transformed by and also transforming of, technologies, techniques, and technical systems. This includes materials and physical forces, as well as 
the ways these come to constitute creatures, plants, and nonliving entities. It also includes abstractions, conceptual feelings, and affects and desires, along with the ongoing double becoming between technics and the social. Finally, and crucially, technics includes the modes of organization, living, and working made available by and feeding back into technical development. Transposing Alfred Whitehead's discussion of "nature lifeless" and "nature alive" (1968, 127-169) into a thinking through of technics, this chapter suggests a tension, through all of this, between two very different sets of tendencies - towards technics lifeless and technics alive. These are only some tendencies among others, and even mainstream technical development is not, of course, all lifeless. However, the tensions between these two sets of tendencies are significant. My main focus will be on media and interactive technics, broadly understood.

\section{NEW MEDIA'S (UNDEAD) LOGIC OF PROGRAMMABILITY}

Resonating with Serres' "aggrieved shame" in "omnipotent impotence," Wendy Hui Kyong Chun writes that the key problem within a contemporary (media) technical culture is an "undeadness" (2011a, xii). For Chun, problems with "new media [are] related to new media's (undead) logic of programmability" (xii). By undead programmability, Chun means that "New media proliferates 'programmed visions,' which seek to shape and to predict - indeed to embody - a future based on past data" (xii). At the heart of this, "information-through its capture in [technical] memory-is undead" (25). Yet decisions, and one could add actions, or simply life, are deferred to these undead bits of stored information. Indeed, we now have a "belief in information as decision" (Chun 2011b, 106). This "decision" conditions and triggers reflex, habit, and more. Thus, undead information contains not only the kernel of calculation and thought as the symbolic processing of this calculation, but also the kernel of process more generally, action and behavior. As technics intensifies, it "catches us" not only in an informational world, but via this, "in a deluge of minor-seeming decisions" (106). Life is deadened by a raft of stilted acts of imposed decision, as we are caught up in often low-level systemic responses based on the intervention of past (often remote, often of dubious relevance) data within the now suppressed situatedness of lived events. This can easily "defer our engagement with crisis" —or, we could 
say, life as lived-or it "renders everything and thus nothing a crisis" in a specific technical sense of prediction, control, and systemic allegiance (106). Here think perhaps of notifications, facial recognition, or the COVID take-up of proctoring software to monitor students at home taking tests.

As such, "programmability" (Chun 2011a, 91) can easily erase much of the process of living life. One result is general exhaustion, accompanied by frustration in attempting to live life while dealing with an ongoing tsunami of technical interference. Apps, interfaces, and larger technical systems fail. Or they simply do not produce the effects they claim to, yet they demand that we engage with them, continuously (just to fulfill the logics of the system itself). Here Chun points to a "kind of exhaustion encapsulated in," for example, "'search overload syndrome'" (2011b, 106). There is a parallel to this, indeed, I argue, a precursor, in the "experimental neurosis" (Todes 2014, 634) produced in Pavlov's dogs when the system provided no solution even as it demanded a response. The dogs had a kind of breakdown.

Within this undead, life-denying technics, many of the looped relations involved are the algorithmic structures of capitalist capture (Knox et al. 2020; Lotti 2019). There are many well-documented problems here. Just one is that technical development often involves inappropriate slippage across fields (e.g., business software being only slightly re-purposed for use within education and thereby changing education in the process [Gulson \& Witzenberger 2020, 7]). Or, to take a more significant historical example, much of the modern logistics, or detailed organization and management of flows and operations, of which many technical systems are a part, was developed within the situation of slavery. As Stefano Harney (2018) puts it:

Modern logistics is a commercial logistics, with all the multiple sources that feed what Cedric Robinson calls racial capitalism.... As a commercial logistics, as a capitalist science, it can be traced directly and emphatically to the Atlantic slave trade. The Atlantic slave trade was the birth of modern logistics, as it was also the birth of a new kind of war on our species being, and the birth of racial capitalism, which amounts to saying the same thing (in Cuppini \& Frapporti, 95-96).

Many argue that the logics of oppression of the development of modern logistics in the situation of slavery continue in contemporary technics (Cuppini \& Frapporti 2018). Meanwhile, the internet increasingly becomes programmed in the sense of a more complex version of television 
programming. Search and other operations are increasingly determined not by the user's 'freedom' or desires, but by the intermeshed interests of capital and other dubious actors (think of Facebook and elections). Overall, it sometimes seems that users are tending towards becoming simply 'the used,' treated by informational undeadness as points of bland intensification for the program. Users are harnessed, not unlike the tightly strapped dogs in Pavlov's labs, to the ongoing programmed low-level capture of attention, 'decision,' and action or even, as famously depicted in The Matrix films, reduced to basic energy units to keep the system going.

How has it come to this? I suggest that the strange lifelessness that often infuses the contemporary condition of technics has a history-with a parade of technical invention that has assumed nature to be "nature lifeless," as Whitehead puts it. Whitehead opposes this to "nature alive." Thinking, lifeless or alive (or even both in various combinations) has obvious implications for technical development. Briefly, nature lifeless refers to an outmoded (even in Whitehead's time) scientific materialism with a fallacy of "simple location" (Whitehead 1968, 139). For one thing, scientific materialism's fallacy of simple location assumes that everything is material (not, primarily, for example, patterns of affective relational events), and "simple location" furthers this. It assumes isolated and relatively inert bits of matter, bodies or objects, exist in empty space. They are pushed around by external forces, with very little else changing aside from things being moved around. These isolated bits of matter, bodies or objects can be neatly ordered in space or sequenced in time, again without too much changing. The bits of matter themselves are "extended, inert, lifeless, valueless, and purposeless" (Smith 2010, n.p.). They "have no experience" (n.p.). A bit of matter; or a body; or an object; or, we might say, an interface; or, to a degree, a bit of programming, data, or information; or anything, in fact, reduced to any of these, "is just there, in that region where it is; and it can be described without reference to the goings on in any other region of space" (Whitehead 1968, 139). As Smith writes, "any interaction between these physical substances is external, like billiard balls bumping into one another" (2010, n.p.).

Nature alive suggests no simple location and no reduction to matter but, rather, densely interwoven relational, affective events. Everything is related to everything else at its core. There is constant process, with "momentarily-developing experiences as the basis of all reality" (Anderson 1995, n.p.). This is an understanding drawn from life itself rather than 
inert deadness. Rather than organisms understood on the basis of Newtonian physics ("billiard balls"), the entire world is understood on the basis of the principles of the organism. To put this another way, while "nature lifeless" and the technics that assumes it attempt to sustain a mappable and predictable, coldly rationalized and next to lifeless system, "nature alive" assumes a complex web of processes of relational events of shifting, always at least partly novel affective events. Of course, nature lifeless and nature alive often come together, but knowing which is which and how they combine is crucial, especially as, at the junction of many social powers and technical systems, there can be a tendency to distribute gradations of liveliness and lifelessness. Different modes of being are judged as more or less alive, with the less alive pushed towards dead in favor of the colonization of the supposedly dead by those who assume life (white settlers, notably). Technics too often comes into this and sustains it (Tallbear 2019).

Although there are, of course, many other tendencies, the de-activating technical tendencies of "nature lifeless" are now found throughout interaction design. Many interfaces seem designed for the next to lifeless - with a programmability that can only re-activate life in terms of the "undead." The broader purpose of this aspect of technics is to accomplish a troubling third enclosure. This creates the conditions for a general extractivism, lived under the aegis of constant constraint and pre-direction, precisely of the ways in which affecting and being affected can take place.

\section{THE THIRD ENCLOSURE AND THE IN-FOLDING OF WORLD AND TECHNICS IN A THIRD MEDIA REVOLUTION}

The first enclosure was that of land (and, let us not forget, of people) as physical property and the second that of intellectual property and thus of creativity, invention, and expression. The third enclosure is far more powerful. It involves the attempt to enclose everything else (Murphie 2014). This technics of living death creates what Paul Edwards (1996) has called "the closed world" - a complicated fractal interlacing of micro, macro, and meso events of closure of the world. In the third enclosure, technics moves to enclose and control all kinds of objects and beings, and all processes and events, micro-events as much as larger events, human and nonhuman, living and non-living. It aims to constrain, if not to destroy and then recreate all of these, within the limits of certain functions and not others, and this within ongoing events of hierarchization of relation. 
The increasing technical precision of enclosure and control allows for increasingly exact and flexible modulations of movements and relations, within direct physical existence, abstraction, and their coming together. As such, technics encloses, or attempts to enclose, all affective events-all affecting and being affected, and all potential to affect and be affected. The final act of third enclosure, now arriving, is empowered by many contemporary technics. Although all the technics involved can be useful (for example, in climate science), it can also perform a reactionary détournement of the world. AI risks enclosing analysis, prediction, and decision and, in doing so, intervenes forcefully, operationally, within many events within the world that would previously have been the domain of human-centered actions. Ubiquitous computing and ambient intelligence support AI by capturing an increasing number of events in the world in increasingly fine and real-time detail. Big data then furthers the enclosure of events by bringing the data from the capturing of events into systems that will cross-reference these events with others. All these systems together can then 'decide' what counts, how it will be counted, and what will occur in response to this counting. VR, augmented, and mixed realities intrude fully into and enclose the perceptions and actions basic to our being in the world, at the very heart of affecting and being affected. Indeed, these technics intrude into and enclose the crucial relations between perception and action in what leads to a complex series of modulated ghostings of presence. Drones, the internet of things, and genetics enclose events and very obviously modulate what occurs in the directly physical world. In sum, the third enclosure is made possible by the dramatically expanded field and massively increased powers of media and communications (Mattern 2018). I have elsewhere called the shift in technics involved-without any great claim to originality-a "third media revolution" (Murphie 2018, 27ff). World and media infold directly into each other, with forces far different to and consequences that far exceed those of the distribution of representations that has been the main characteristic of the mediation of culture since the printing press. We are leaving the age of representationalism and everything that this has implied.

Shortly, I will give a detailed account of a well-known stream of events I will call Pavlovism. I will discuss Pavlov's work, but 'Pavlovism' also gestures towards something that exceeds Pavlov-precisely, a series of technics designed to produce near lifelessness. These involve actual assemblages but continue beyond these as a series of "agencements" that 
increase "the multiplicity of [their] conceptual and social (and aesthetic) dimensions" as they expand and change their "agencies via connections with other machines both technical and social" (Mackenzie \& Munster 2019, 6). An expanded Pavlovism continues up to this day, reinforcing the lifelessness of much of contemporary technics. It is not always understood that Pavlovism begins with a sophisticated interactive set-up, a kind of ur-interface (not the only one) for the severe constraint and control of the animal.

\section{TECHNICS OPEN TO THE INFINITE AFFECTIVE VARIABILITY OF WORLDS}

There are many subtler and more world-/other-responsive approaches within interaction design and technical development. Even from within an otherwise lifeless technics, these approaches find potentials for "nature alive." These approaches give rise to a technics that can modulate complex differentials within and across multiple ecologies. They eschew the fallacy of "simple location." They tend away from calculated control. They tend towards relational attunement to the always entwined powers to affect and to be affected. They are thus far more open to the infinitely variable affectivity of the world - its liveliness - than the like of Pavlovism's push towards a technics of the lifeless (although Pavlovism is so common that all modes of interactive design need some vigilance with regard to it). These approaches are more able to fully and differentially respond to the immanence of events and their situatedness. The best of them precipitate in-world events that include a fugitivity from cold rationalities, in favor of feeling immersed deeply in the life of the world (Harney \& Moten 2013).

Many critical accounts of approaches to interaction sketch out principles for this different technics, with hints of the potential for a design to come (e.g., Amaro 2020; Benjamin 2018 \& 2019; Boyle 2018; Costanza-Chock 2020; Goodman 2020; Heilig 2019; Lotti 2015; Manning 2020; Parisi 2013; Pascoe 2014; Penn, McNealy \& Running Wolf 2020; Plumb 2016; Tallbear 2019). There are also many exploring the specifics of building such a technics. These are found in the more radical aspects of interaction design and design more generally, in activism, in interactive arts, and in music. Others exploring radical design and technics are found in minor socialities and in many recent challenges to the standard technics of organization in, for example, platform cooperativism (Scholz 
\& Schneider 2017), Data for Black Lives Matter ${ }^{1}$ or First Nations' data sovereignty (Kukutai \& Taylor 2016). All this activity-both the different abstract principles involved and the more direct work on design projects and processes - makes for a kind of loosely woven movement (principles, technics, and the like of data are often shared). This movement resonates, if differentially, with other movements involving open sharing of technics and data, as found for example in some complex scientific research, such as climate change. This movement is both global and hyperlocal. It is a movement for permanent change within the world yet one able to respond specifically to the moment. It is diverse. It is inventive in the sense of the "speculatively pragmatic" (Massumi 2011, 13). It works towards a new belief in the world and towards a people to come, sensible to this world. We owe those working on such projects of fugitive technics a deep debt of gratitude for the potential avenues of escape they open up within what can sometimes seem to be oppressive technics (e.g., Bertelsen 2012 and in this book; Brunner \& Fritsch 2011; Dourish \& Cruz 2018; Fritsch 2011; Fritsch, Loi \& Light 2019; Lotti 2018; Manning, Munster \& Stavning Thomsen 2019; Rogers \& Marshall 2017; Running Wolf \& Running Wolf 2017 \& 2019; The Design Studio for Social Intervention 2020; Wakefield 2020). ${ }^{2}$

There are many examples in this volume of this movement towards a more sensitive, genuinely open, and, in many ways, humbler world-immersed technics. Such examples, and the friendships and working partnerships I have been fortunate to experience with the people involved, have inspired the final sections of this chapter. These outline the potential, in again a kind of fugitivity, towards re-learning from the inter-affectivity of the world itself, from elephant feet as interface, for example. Inspired by this more world-aware and sensitive approach to interaction, affect, and event, I will conclude the chapter with a sketch for a manifesto for the future of that-which-we-currently-call-the-interface. First, however, I will discuss that with which all technics currently struggles - Pavlovism. 


\section{PAVLOVISM}

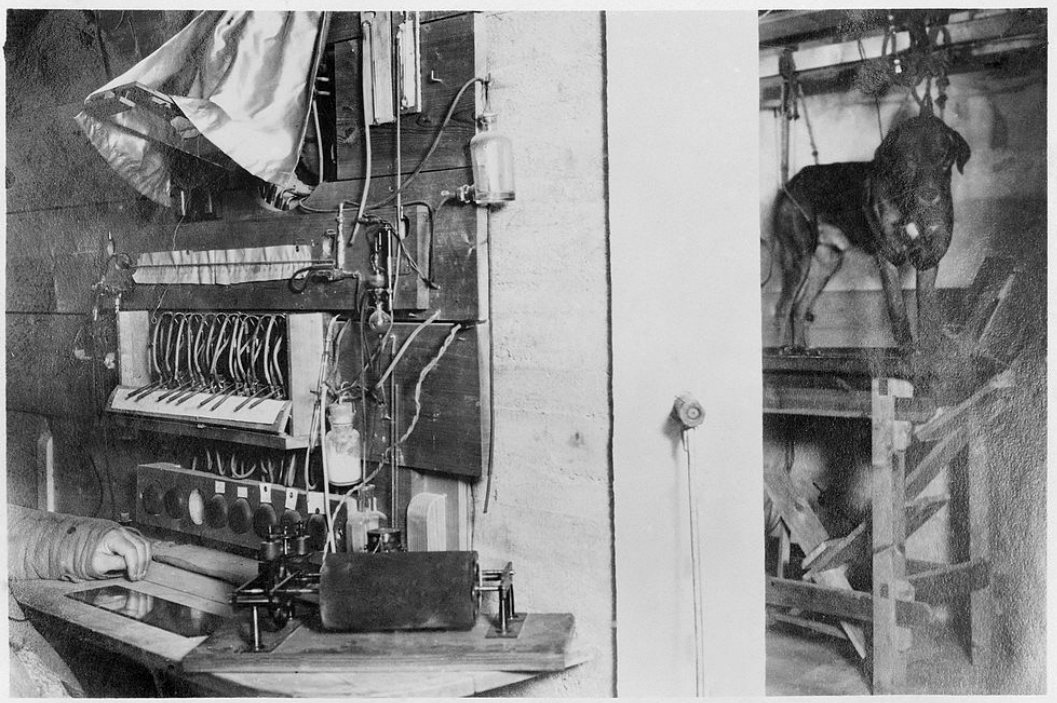

Figure 1. I.P. Pavlov's Laboratory, concrete suspended room with door open and dog in position (top). Figure 2. I.P. Pavlov's Laboratory, manometer reading on outside of door to dog room and operator looking through periscope at dog inside, Dr. Pavlov seated (bottom). ${ }^{3,4}$

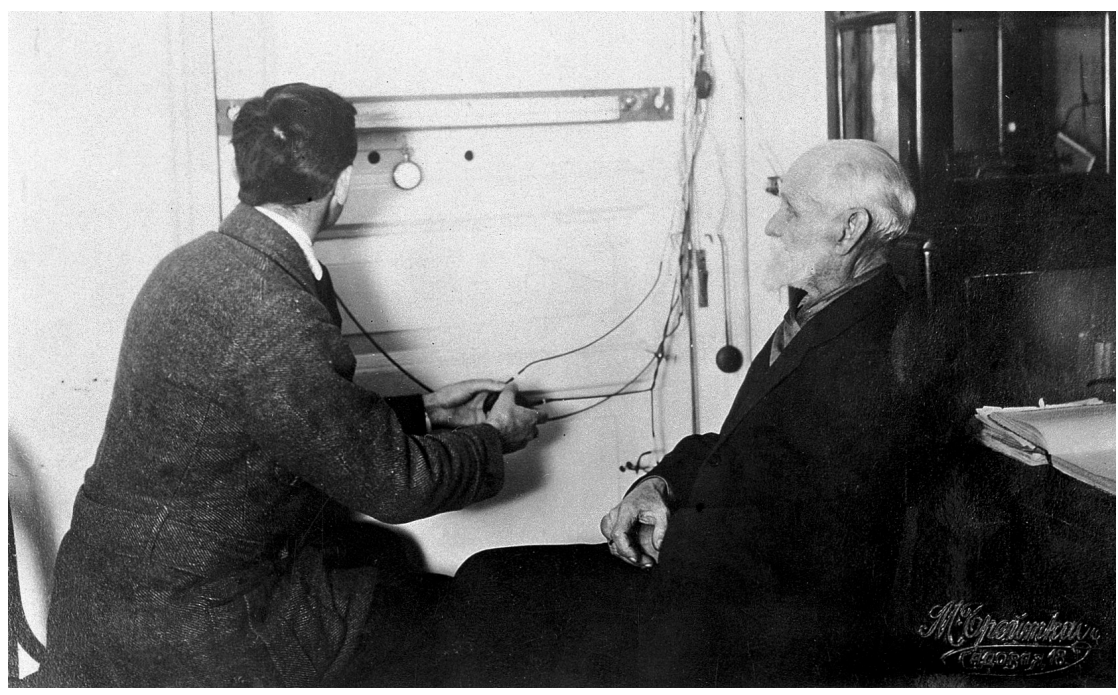


Pavlov's achievements were not restricted to the 'discovery' of the 'conditioned' reflex. More importantly, he created, not only in but as his laboratory, an entire assemblage and indeed a series of interfaces or interactive devices that could induce a conditioning of the reflex (among other behavioral events, including the deliberate induction of breakdown). It is this assemblage - including the very idea of such an assemblage - that provided the basis for the subsequent Pavlovism so influential within the technics with which we now live. The conditioned reflex, which Pavlov himself actually called the "conditional reflex" (Todes 2014, 1) precisely because it was contingent on the situation, is really a part of an entire technics for the induction, conditioning, and then potential (re)organization of behaviors or, more broadly, events of affecting and being affected.

Pavlovism emerges not only from Pavlov's lab, but also from those performing similar research-such as Thorndike, Skinner, and Watson. I suggest that we can also see elements of Pavlovism present within the series of assemblages that helped constitute computing, neuroscience, and 'cognition.' Indeed, I will suggest that most aspects of Pavlovist technics, including the ability to self-perpetuate in variation, come to form a key part of what we might call the 'major technics' that follows ('major' in the sense of dominant, hierarchizing, and homogenizing). This includes Pavlovist schematics, principles, and propositions and, indeed, their conceptual creations and the conceptual feelings with which they can then be lived. It includes Pavlovism's curtailing of lived experience and the killing of relation beyond the severely restricted kinds of relations Pavlovism forms within highly enclosed worlds. In general terms, the animal, including the human animal, becomes a limited "machine in the middle" (Edwards 1996, 175ff) of a more complicated system in which it participates via the induction and ongoing modulation of basic reflexes. In this light, it is worth noting that Pavlov conceived of the operation of the nervous system and its reflexes on the basis of the telephone exchange (Gerovitch 2002). He also thought reflexes to be the basis for all psychology and, in this respect and others, thought of dogs and humans as analogies of each other (analogies becoming a fuller technics in the cybernetic broadening of behavioral loops through "animal and machine" [Wiener 1948]).

What follows is a schematic summary. 
There was no bell (Todes 2014, 1); not really, though there were carefully calibrated buzzers, and there were electric shocks and much worse. The dogs were constrained by a leather harness on a lab bench. Gregory Bateson pointed out that the dogs did not, in fact, salivate without this constraint (1987, 253). The dogs were also isolated (enclosed). Neither Pavlov nor his assistants were in the same space. We know that dogs are profoundly social creatures. Yet here, the social is destroyed. Events are

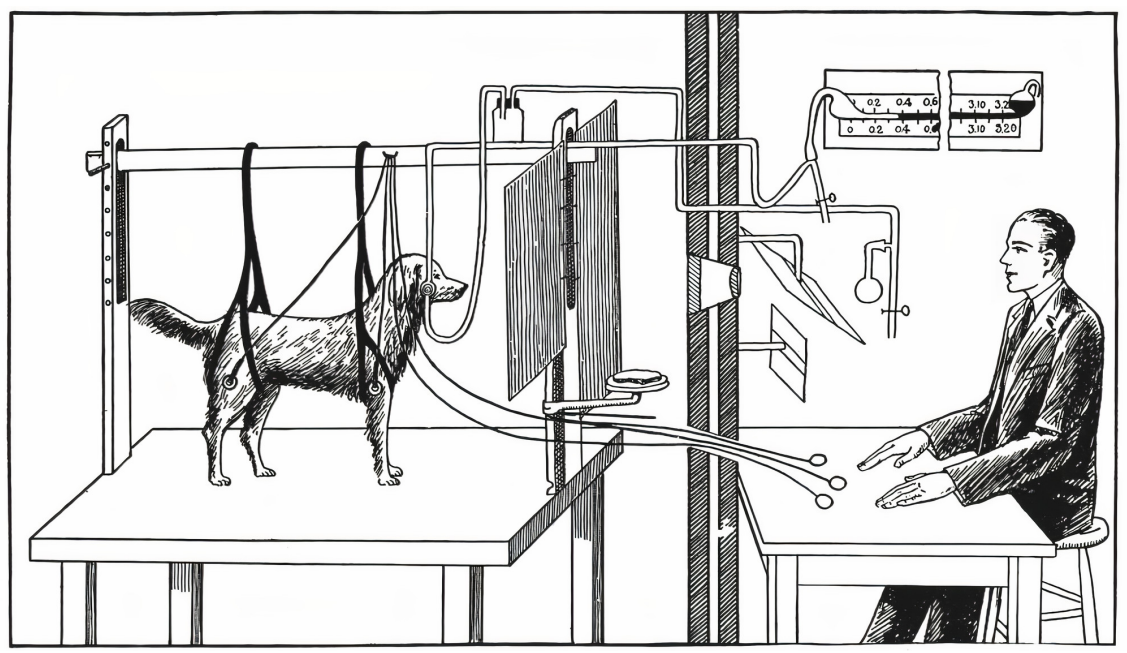

Figure 3. Diagram illustrating Pavlov's experiments with a dog, $1928 .^{5}$

controlled from outside the situation through wires and switches and mechanics: in other words, complex interfaces ('ur-interfaces'). 'Operators' watch - like drone pilots and data analysts now-from a distance, through a periscope or via observing the manometer, which measured pressure changes indicating the flow of saliva. At the same time, the operators' own enclosure in the system, if at a different point within the assembled and activated hierarchy, should not be missed. It is easy to see 'softer' parallels with our own constraint, isolation, and enclosure by our devices and with the restrictive hierarchies that now substitute themselves for social relations in work and, increasingly, in life. In fact, I hope that in what is detailed below, it will become clear that Pavlov's laboratory set-up as a whole-as much as, if not more than, the reflex induction 
and conditioning - provides a clear diagrammatic precursor to 'big tech' now, along with many other contemporary forms of organization (this increasingly includes the organization of academic practice). The laboratory also provides the basis for many subsequent variants-Skinner boxes and mazes; Seligman's electric shock box, also for dogs, to induce "learned helplessness" (positive psychology simply inverts this); and so on. And so much of this comes into basic assumptions within interaction and interface design. We too often tend to become the experimental animals within a broad social Pavlovism, from whom much is being extracted at the same time as conditionings tighten (extracted from us as individuals, as social, as political, as communicative, as signaletic, as bodies, as stretching between the directly physical and the abstract).

The isolation enables the dog to become an exemplum for the technics of a forced individualization. This goes further, however, than the 'individual' as we usually think it (although it does include this). The production of individualization comes to mean the production of any useful reduction to and, in fact, manufacture of individual elements (down to individual reflexes and other behavioral events) insofar as these can be broken away from each other. This breaking apart also produces a kind of de-worlding of these elements. These elements are precisely not those of the complex, broadly relational self but rather those from which a new kind of limited 'individual' being can be built. It is here that we can make sense of the drive towards isolation and control of the reflex. It is perceived as the ultimate basic element of behavior, of biological events as these can be programmed to engage with the world. Here is the ground zero of the deadening that becomes "undead" media. The reflex is worked as a kind of phoneme at the very limit of already highly limited activity. This is activity that barely has content. The micro level becomes crucial, in what Brian Massumi has called an "ontopower," exercised within "bare" - that is, almost contentless, only just emerging - "activity," "barely there" $(2015,44)$. Controlling this becomes the key not only to the modulation and control of the individual, but also to the ongoing attempt at re-creation of a compliant individual (and the social as a machine) from these basic elements up.

From this, behavioral worlds seem to be able to be built and indeed, with all their flaws and dysfunction, have been built, from only a few very basic elements. The very concept, accompanied by a now immense variety of Pavlovist technics to isolate and then work with these elemental 'building blocks' of behavioral processing, has worked its way into many ecol- 
ogies of practice. Such processing has become a key part of working with the nonliving as much as with the living (in what, for example, could be called computational behaviors). In all this, the conditional reflex becomes an exemplum for a de-worlding and elemental breakdown and individualization of the complexity of the body-world relation. The body-world relation can then be reterritorialized on the technical system in which it will be reassembled (as is the dog in the laboratory). This will enable the general cultural take-up of the cultivation of specific responses within technical systems through the like of reflex control in classical and operant conditioning ${ }^{6}$ and so on. However, beyond this, it will also enable a general distribution of events through the aggregation and matching of the 'behaviors' of machines, as well as nervous systems, via technics, including those of interfaces and networks. This is a Spinozan technics, in that it conceives of every kind of affect as able to work equally across a field of body and mind. Yet it involves an anti-Spinozan ethics, in that the technics is specifically designed to cut almost every aspect of creatures (and, in some ways, technics itself) off from the wider world of affecting and being affected.

Learning, according to Pavlovism, is a reductive technics that breaks events down into basic responses (obvious behaviors but also appropriate thoughts and feelings, considered as behaviors). It then re-assembles them accordingly in a newly intensified, Pavlovist mode. This becomes a major force within education, one that then continues into general culture (life-long learning; managerialism) (Gulson et al. 2021; Know et al. 2020). Whatever its alternatives, it has been hard to escape it since.

Several other of Pavlov's dangerously reductive assumptions have remained baked into a great deal of technics. These often lead to general inflexibility and dysfunction, even as they lead to the kind of predictable, narrow range technical effectiveness that is a part of their success. One of these assumptions is that of relatively static systems. This includes the nervous system. That is, it is assumed that systems, including the nervous system, are relatively simple and static and that, for example, once a reflex is induced behaviour will then change, but only to a new form of simple repetition. Controlling situations to induce such simple repetition in relatively static systems therefore becomes key to the control of events. Bateson, for example, was highly critical of Pavlov on this and other points, writing that "to the 'pure' Pavlovian, only a very limited fatalism would be possible" (1987, 180). Indeed, he criticized Pavlovism in Western culture 
at large, writing that, "[I]t is a little hard for members of Western civilization to believe that whole systems of behavior can be built on premises other than our own mixture of instrumental reward and instrumental avoidance" (179). More generally, Bateson thought that signal, communication, learning, and "interactive sequence" (310)—assembled together so rudimentarily in Pavlov's laboratory - were far more complex than Pavlovism had constructed them to be, and that Pavlov's influence had led to some especially unfortunate understandings of all of these. What were missing were, again, life and world, specifically the complex ecologies of signal, communication, learning, and interaction found in the life-world situations that Pavlov had specifically excluded (Harries-Jones 1995, 148).

Another unfortunate assumption of "Pavlovian fatalism" was that, within this supposed static system, the complexity of response to the world could be reduced to the control of simple reflex events and this via a simple turning on or off of reflexes, on command, via an interface. There is no doubt, of course, that Pavlov's laboratory successfully engineered the induction of basic, isolated on-off states in a series of flows that were, however, treated like flows in plumbing that could effectively be turned on and off as with a tap-flows of behaviors, feedbacks, stimuli, responses, and of saliva and other gastric juices and bodily products. ${ }^{7}$ When Pavlovism mutates and merges with other assemblages (such as those involving logic and calculation), it creates aspects of what will become, in related but slightly different ways, neuroscience, cognitivism, and computing. All of these, via mini-events of 'processing,' assume a combination of calculative logics with the modulation of living/nonliving behavioral events via feedback. It is a surprisingly short distance from Pavlov's conditioning of reflexes to the crossing, or not, of thresholds of electrochemical excitation in neurons that would be more fully described by McCulloch and Pitts (1943). Their logical calculus of the ideas immanent in nervous activity combines assemblages of logic with gated neuronal behaviors. A general calculative-behavioral program, across animal and machine, develops. ${ }^{8}$ A useful and effective, but highly reductive, on/off programmatic understanding is imposed on the nervous system. This (impossibly) attempts to corral, within the programmatic, the interwoven and shifting patternings of responsiveness within the nervous system, and to the world, indeed the cosmos. The attempt is to control what I have elsewhere suggested should be understood, not as a rationality in the sense of delimited logics, but rather a proprioception in the brain (Murphie 2019) ${ }^{9}$ enmeshed in world. 
In turn, cognitivism will generalise, re-organise and rebadge this so that Pavlov's stimulus and response technics will become 'cognitive' or 'information recall' and so forth. It is arguable, then, despite the anti-behaviorist rhetoric at its foundation, that cognitivism was only ever a complicating variant/extension of behaviorism (or at least of cybernetics' expansion of behaviorism [Dupuy 2000]). Indeed, cognitivism in all its forms is arguably now a key part of a general cultural Pavlovism. Cognitivism provides a kind of distractive cover-all over more basic, wide-ranging behavioral controls.

In a similar fashion, it is also not so far from Pavlov's induction of on-off states in reflexes to the on-off surges and retreats of voltage within computers to come. Famously, in what is another 'ur-interface' for almost everything that has followed in communications and interaction, Shannon domesticated the behavior of signal so that it could faithfully transport 'the digital' of 1s and os. Turing, for his part, is sometimes loosely considered a behaviorist, partly because the Turing test is essentially about passing behaviors and partly perhaps because his design for actual Turing machines involved a kind of coded stimulus-response framework at its core. It is this that then leads to the higher level stimulus-response behaviors found in the Turing test and, indeed, to what is often called interaction. Through all these areas, there arose the possibility of sequencing such elemental on or off flow-states via a technics of 'stimulus-response.'

Indeed, the transversal movements and mutations of Pavlovism potentialize technics as a whole. The processes of reduction and sequencing and complication seem to be able to play across any situation (although the word 'seem' should be emphasized). Within and across bodies, machines, and world, Pavlovism seems to enable reflexes and habits, affecting and being affected, nervous system and brain events, voltage shifts and 'symbolic processing' and 'interaction' to combine. It creates the possibilities for a highly, if variably, regulated physical-socio-technical world.

In sum, in animals and machines and in between them, and under the aegis of control and communication, as Norbert Wiener put it (1948), all kinds of flows and events could now be broken down and isolated from their usual situatedness into elements of process. These elements of process could then be processed (via turning them on and off in sequence). This could be accomplished via interfaces and algorithms and social systems. These processes could then be broken down again and worked within and across different assemblages and again sequenced and controlled. Indeed, 
what was happening in Pavlov's laboratory was already processing, and already in a sense a basic symbolic processing (as Lacan, for one, suggested [Zwart 2018]). It was already a kind of (close to lifeless) computing. Here it is also perhaps important to emphasize that actual reflexes were, in fact, not only behaviors but also literal signaletic movements between the internal (nervous systems, glands, muscles, and so forth) and external. In other words, in this set-up, reflexes become technically assembled movements of inputs, processing, and outputs. Yet still, despite the many variations and some openings to dramatic complication, all of this carries with it the basic problems of Pavlov's severe reductionism. It renders everything involved, including computing and interaction, 'lifeless.'

This leads to an extremely complicated culture but not necessarily a complex culture. To put this differently, it does not always lead to a culture possessing the ability to respond to the open, relationally complex world. Indeed, cultures - work cultures, social cultures, political cultures, educational cultures, and even technical cultures such as those of Silicon Valley-can become somewhat brittle in the face of complex problems, including those problems posed by technics itself.

As suggested previously, Pavlov was not, of course, only interested in conditioning reflexes. Among other things, he also explored the ability to induce psychological breakdown in the dogs via electric shocks, predictable and unpredictable, and other methods. Part of this involved the induction of a kind of "experimental neurosis" (Todes 2014, 634), a kind of warping of learning that has unfortunate echoes today in education (for example, in a deeply disturbing physiological-perceptual double bind [Bateson 1987, 301]). A simple way to understand this is that Pavlov was experimenting with extreme stress limits. By this, I mean a limit from within and, in fact, as structured into a specific assemblage, beyond which a creature literally cannot go without breaking down. Crucially, the process is at the level of habituation, and consciousness has little or no access to what is going on. This in-structuring of stress limits combines with the structuring of reflexes to further the production of hierarchies and in-groups/out-groups as stress-limited habituations. One result of this today is 'performance management.' There are many others. Indeed, this combination of breakdown limit and the organization of reflexes is strongly present within much socio-political programming, not least as cultivated by so-called 'management science' and prominent social media platforms. 
Pavlovism goes yet further, in an even more literal extractivism of the body. For example, in one of many particularly gruesome and cruel procedures, Pavlov opened the dogs' esophagi so that food could never reach its destination. This enabled the continuous production of digestive juices. These were sold by Pavlov's laboratory as a supposed cure for dyspepsia. Again, slightly abstracted, one might suggest that this provides a very crude diagrammatics for that which we sometimes now call technology addiction (in which instead of inducing a continuous production of digestive juices, technics induces a continuous production of signaletically attuned attention, as found in endless scrolling and swiping, for example). One bridge between Pavlov and now in these terms has been Skinner's extension of these operations into operant conditioning, ${ }^{10}$ in gambling and more generally as a part of interaction design (Dow Schull 2014).

Through all this, we see the beginnings of what I would call 'pre-automation.' Pre-automation means two things. More generally, it indicates that a deep, fundamental automation has occurred before the more obvious full technological automation we are so often told is now arriving (in AI, robotics, etc.). In other words, automation 'arrived' long ago and has long intensified itself, within us and deep within our own ecologies of working and living. It is even perhaps found within some of the diagrammed versions of 'individualism' and the supposed attached 'freedoms' that some have come to treasure. These are often assembled precisely as part of our (at times unwitting) participation in a general Pavlovian technics. This is a perverse freedom to take part in a world of highly structured hierarchies. Ironically, this is a 'freedom' in which, partly because of Pavlovism, increasingly little is left to chance, which is to say not subject to a deadening programmability. Secondly, pre-automation suggests a specific range of programmed events (e.g., skills) and collections of programmed events (e.g., expertise) via which we now work and live. This will, in fact, make it easier for full automation to occur, that is, a going beyond our behavioral automation to our full replacement. Ordering behaviors and responses to the world into basic elements and then reassembling them into restricted and highly ordered diagrams and taxonomies allows things to more easily be 'learnt' by machines, specific skill/expertise by skill/expertise. For although Artificial General Intelligence is still at least decades away, AI already performs well, in its own terms, within specific fields of expertise. If we already assemble ourselves to operate algorithmically, why would an algorithm not 
be able to replace us? There is, for example, enormous danger in precisely this respect in the contemporary prominence of behavioral-cognitivist forms of organization within education, as education attempts to engage with the 'future of work' (Gulson et al. 2021). If education is organized according to these principles, down to such questions as "what skills do we need to meet the future of work?, " we are essentially meeting automation by speeding it up. We risk making students more replaceable by educating them via forms of organization and modes of thinking and behaving that induce lifeless lives, which are those most easily replaced.

From within Pavlovism, during World War II, B. F. Skinner tried to develop a pigeon-guided missile system, in one of the early "learning machines" (Ferster 2014, 68ff; see also Watters forthcoming). Skinner himself later called Project Pigeon, as it was named, a "crackpot idea" (Ferster 2014, 68). However, many of us are now pushed towards becoming such pigeons, pecking at screens, directing our classes towards learning objectives or our lives and work, institutions, or national economies towards the fulfillment of performance measures. Project Pigeon was later called Project Orcon, short for "organic control" (Skinner 1960, 29).

Pavlov also possessed a passion for data (Todes 2014, 96), which becomes another form of control. A pioneer of biological experimentation in Russia, Pavlov extracted a wealth of data, as it is usually understood (measures of salivation, etc.) from the experiments. Yet he also created methods (carefully timed buzzers and shocks, dogs trained differently to slightly different audio tones, etc.) for inducing predictable physiological-psychological responses to stimuli. In the latter, he arguably begins to convert the body and nervous system themselves into data. That is, physiology and psychology themselves become aggregations of 'givens' interchangeable with other modes of the given (the basic meaning of the term 'data' is 'the given') (Kitchin 2014, 2). All this has influenced the corporate, institutional, and governmental assemblages with which we increasingly live today. Throughout, there is a structuring of relations within what we might call a powerful and diffuse "ecology of bad ideas" (Gregory Bateson, quoted by Félix Guattari 2000, 27).

In Pavlovism, we also find the ways in which various closed-world assemblages and diagrammatics for further assemblage become actively self-sustaining, operationally. Pavlovism's variable technical means produce ongoing closures within events at the same time as they further the social reproduction of Pavlovism itself. It's one thing, for example, 
to have the idea of closed economies that extract/refuse what they want from externalities such as the environment or social lives that are populated by appropriately behaving individuals. It's quite another to develop an assemblage to make that work, ongoingly.

The powers that assemble themselves in Pavlovism enable a powerful form of capitalist extraction not only of behaviors and gastric juices, but also of data and of the very conceptual feeling of living within assemblages that will become entire control institutions, societies, platforms, and of all of these intermeshed in and becoming one another.

\section{TECHNICS LIFELESS AND ALIVE}

Pavlov ... grappled with the difficulties of keeping his experimental animals alive after surgical operations.... The development of techniques to keep such valuable experimental animals alive for years, and the recognition that some animals simply made better experimental subjects than others, would become central features of Pavlov's mature physiological style (Todes 2014, 63, 65).

These techniques would also become central features of contemporary technics. Who gets to be kept alive (under certain conditions), and who is a better fit within such a technics? For what kind of culture, science, or philosophy does such a technics assemble itself? Here we can briefly turn again to Whitehead in order to orientate ourselves.

First, Whitehead notes a key problem in modern culture, science, and philosophy - in what he terms a bifurcation of nature: into nature apprehended and nature apprehending $(2004,29)$. Didier Debaise suggests that this is a deeper problem than that of the body-mind split (2017, 3ff). This bifurcation becomes the basis for so much that follows (hierarchy, of course, but also misunderstanding of the nature of the world). Nothing could more clearly illustrate this than the dog and its conditional reflex as nature apprehended. Indeed, the point seems to be the severe subtraction of the dog's ability to apprehend and to construct, within this assemblage, Pavlov as nature apprehending. This is not a natural order of any kind. It is an operative structuring. Yet it is an operative structuring that Pavlovism has helped to naturalize.

In addition, in that it is an active but destructive structuring and especially in that it blocks access to richer (more alive) aspects of the world, Whitehead would probably have considered it 'evil.' For Whitehead, evil is very much situational, a question of how things are ongoingly assem- 
bled. He writes, evil "is positive [active, processual] and destructive; what is good is positive and creative" $(1926,96)$. The "nature of evil is that the characters of things are mutually obstructive" (Whitehead 1978)." This is how things are in so much of Pavlovism, most obviously in the constraints and the sophisticated production of "experimental neurosis" (Todes 2014, 634) that Bateson thought an experimental incidence of the famous double bind.

Second, in Modes of Thought, Whitehead notes that most of what has become modern science, as in Pavlovism, has a concept of nature "under an abstraction in which all reference to life was suppressed" $(1968,144)$. As noted earlier, this has been in favor of predictable relations and event-outcomes between relatively independent and in themselves relatively inert elementary particles (like atoms in early physics). The relational aspects of all events, which mean that no event (or entity) has "simple location," along with the creative aspects of life, were replaced by isolated, individual elements, with activity at best "bare activity" (e.g., the conditional reflex). For Whitehead, "there are no instants, conceived as simple primary entities, there is no nature at an instant" (146), just as there is no simple location and no simple "individual." Rather, there is the ongoing "inter-relation of all matters of fact," and this "must involve transition in their essence. All creative realization involves implication in the creative advance" (146). When such things are ignored, it is no wonder that we end up with "technics lifeless."

For technics to become alive, then, we need a technics that un-bifurcates nature or simply refuses the assumption of a bifurcated nature. It would be a technics that opens activity to content, by which here I mean not so much to more of what is 'represented' as to the ongoing variability of novelty provided in engagement with the open world. This is fundamental to questions of technics and of 'interactivity' and 'assemblage' although to travel in this direction means challenging how these are often conceived and operationalized, to the point that we perhaps are thinking what comes after many of our given understandings of interactivity, after assemblage, and perhaps even after technics.

The 'fundamental question' then, a fundamentally different question to those that motivate Pavlov's assembling of interactive frameworks and technics via which to instantiate the constraint, emptying and zombifying of activity, is how "do we add content to the notion of bare activity? Activity for what, producing what, activity involving what?" (Whitehead 
$1968,147)$. Whitehead's answer is simple - the content we need to add is "life" (147). More specifically, it is "fusing life with nature" (166). This is not only a matter of rethinking things or of a different 'model' for interaction. For Whitehead, "conceptual experience ... is only one variable ingredient in life" (166). The deeper aspect of life is the fuller (self)- "enjoyment of emotion, derived from the past and aimed at the future" (167). In other ways, the deeper aspect of life is the transformative movement of affecting and being affected, a creative coming together of intensities with novelty in-world. 'Interactivity' is replaced by "an activity of concern" that "although engaged in its own immediate self-realization, is concerned with the universe" (167).

\section{ELEPHANT FEET}

It may be useful to briefly contrast the regressive technics of the third enclosure with what is left of the open world 'in the wild.' Here, technics (or what, in some ways, exceeds our concept of it) finds expression in an entanglement of appropriate opening/closure that is world supportive. This enables a movement-with the world as it changes, in a rich and flexible adaptation from within the immanence of events. Hierarchies often give way to shifting 'heterarchies' (Harries-Jones 2016, 105ff). This allows for a general complexity that in turn fosters a much greater degree of flexibility within the emergence of events - "bioentropy" in Bateson's terms (Harries-Jones 2016, 15ff) or "response-ability," as Donna Haraway puts it:

Response-ability is that cultivation through which we render each other capable ... the cultivation of the capacity of response in the context of living and dying in worlds for which one is for, with others. So I think of response-ability as irreducibly collective and to-be-made. In some really deep ways, that which is not yet, but may yet be. It is a kind of luring, desiring, making-with (Haraway in Haraway \& Kenney 2015, 230-231).

Part of the enhanced response-ability of the open world is a kind of pre-/post-interfaciality, a work with interaction much larger than the interface per se. This bypasses the primacy of the interface that until recently dominated a closed technics (although this is changing in its own way as technics becomes ubiquitously (invisible'). This can circumvent the limits of overly closed systems. Undead media too often just respond to the world with a kind of confused complication of the predetermined. 
A 'wild' minor technics would learn from technics in the wild. Andrew Goodman suggests this would allow us to rewild the world itself and therefore re-enliven so much, including perhaps technics itself:

\begin{abstract}
Rewilding emphasises the potential of dynamic and complex ecologies with intensive capacities to collectively experiment with flux.... Here rewilding is an ecological practice squarely addressing the field - not through control but through an understanding of the capacity for self-organization that exists within complex systems in certain states $(2019,134)$.
\end{abstract}

The wild is that which exceeds the simpler and often more reductive, even if complicated, overly hierarchical orderings to which it is often subjected. This wild involves a complex mix or "gathering" of ecologies (Goodman 2018) ${ }^{12}$ and, at that, a gathering of very different kinds of ecologies, even as they coincide within the one event in the world.

There is another way to rethink the interface in this situation, not by-passing it so much as multiplying it. In the wild (and this includes our own bodies), interfaces or what far exceeds the very notion of the 'inter' or the 'face,' are everywhere. They are found across every surface and in every depth, to the point that everything is 'inter.' Indeed, 'inter' no longer makes sense really if there's nothing to be 'inter' between (Massumi $2011,39 \mathrm{ff}$ ). It is more a question of how everything affects and is affected by everything else. To re-wild is to diagram potentials differently within this, immanently.

Consider a few hints of what a pre-/post-/alt-technics might be within this re-wilding. It seems that, in addition to their regular hearing, elephants can hear through their feet. This includes hearing seismic waves from many kilometers away (Kennerson 2018; O'Connell-Rodwell 2007). They may also hear storms over 150 kilometers away (Kelley \& Garstand 2013, 352) or the movement of other animals. Other animals communicate seismically as well (e.g., spiders, scorpions, kangaroo rats, and golden moles).

Or consider whales and dolphins. Without much at all in the way of technologies per se, they have a rich and effective communicational ecology that is in many ways "stranger than anything we could have conjectured" (Durham Peters 2015, 57). They live in an ocean that is "the primordial medium-free zone, immune to all human attempts at fabrication" (Durham Peters 2015, 54). Yet this is also an incredibly rich meta-medium, as "the ocean is the medium of all media, the fountain from which all life on earth emerged. Life in all its varieties pays homage to the sea in 
its structure and function" (54). Here, 'inter' or 'face' or 'interaction' or media or communication or technics or organization are assembled very differently. As Durham Peters points out, whales and dolphins are:

[s]trange creatures, that hear with their jaws and vocalize with their noses! For humans, the face is both an organ of emotion and an ethical claim to personality, but whales cannot even look at each other face-to-face. Even binocular dolphins do not have faces as we do. For one thing, they might not see well enough in the water, though they can recognize themselves in mirrors. More importantly, their faces cannot produce visual displays of emotion (67).

Such strangeness, beyond the human and certainly beyond the very limited conceptual and configurational capacity of much of our current technics, is abundant in the wider world. To take another example, flowers can, in a certain sense, 'hear' bees, and it may lead them to sweeten their nectar (Donahue 2019). Forests, along with their mycorrhizal networks, are filled with complex intra-/extra-communicational events. ${ }^{13}$

In sum, elephants' feet, cetaceans, flowers, and forests suggest the potential for a minor technics involving the constant creation of interfaces (or better, relations beyond the inter- and -face of interface). These would be far more adaptive to a variable and open multiplicity. It is difficult even to conceive of comparing what thinking and feeling might be here with the impoverished assemblage of reductionist events of enclosure we call 'cognition.'

The contrast with some of the stronger influences within much mainstream technics is stark. For while dolphins are swimming and playing and socializing, we are still ridiculously constrained, for too much of each day, by the old-fashioned nature of keyboards and screens and basic buttons and swipes. We are increasingly subject to impoverished ecologies of abstraction that enclose, individualize, and control via the simplistic and regressive scripted behaviors of the contemporary workplace and the like of its 'key performance targets.' We are increasingly pre-automated. The 'third enclosure' continues, via a massive and complicated Pavlovist pile-up of what, despite the enormous complication and power involved, is often made up of very numerous but nevertheless quite simplistic algorithmic-communicative events. Too often, unable to deal with real complexity, this only leads to contradiction and dysfunctionality.

At the same time, many aspects of this will soon disappear into a third media revolution, as described previously. Everything is once again "melt[ing] into air," as The Communist Manifesto famously put it (Marx \& 
Engels 1977, 39). We are once again "compelled to face with sober senses" our "real conditions of life," and our "relations with" our "kind," along with our relations with those not of our kind (39).

\section{TECHNICS ALIVE}

As I suggested towards the beginning of this chapter, there is a great deal more to technics than Pavlovism, even in the 'West.' Yet a series of Pavlovist tendencies persists. Are there any fugitive potentials from within this? If so, where would they take us?

In the early 1970s, Samuel A. Corson and Elizabeth O'Leary Corson were continuing their decidedly Pavlovian research into stress, using dogs in a laboratory. The floor above their lab was a psychiatric ward. The dogs barked and could be heard in the psychiatric ward. Some of the adolescent patients heard this and wanted to play with the dogs. Meetings between dogs and psychiatric patients turned out to be highly beneficial for the patients (who, for example, began communicating). They were also, one hopes, good for the dogs. The Corsons became key to the development and popularization of pet therapy (although it had existed before this) (Chandler 2017, 30ff \& 128ff).

Comments made by Deleuze in a conversation with Foucault resonate both with barking dogs and perhaps with teenagers in psychiatric wards:

If the protests of children were heard in kindergarten, if their questions were attended to, it would be enough to explode the entire educational system. There is no denying that our social system is totally without tolerance; this accounts for its extreme fragility in all its aspects and also its need for a global form of repression (Foucault 1980, 209).

So it seems that fugitivity can be found in protest (barking, the protests of kindergarten children), but this needs to re-establish itself in the social, in the Corson case via play. This rekindles response-ability across dimensions and allows re-entry into the world at large in the literal dismantling of the isolation key to global forms of repression. Perhaps with pet therapy, however, we are only part of the way there.

Two comments by Donna Haraway take us further. They take us towards a technics absorbed into the world. In a wonderful documentary made recently by Fabrizio Terranova, Haraway discusses her now-ageing dog, Cayenne, who is barking. Haraway (2017) says: 
And what she's doing now is canine cognitive dysfunction. She's a little bit senile. And she starts barking, in a little bit of confusion. In the late afternoon. She doesn't exactly quite know what to do with herself. And what I hear is my old friend, a little bit confused. And the barking ... reminds me of the detail of the intimacy, or inheritance. That's the inheritance of big things and little things, the different life spans of a woman and a dog. That we've all flamed together for 10 years. And that she's old, in a way I'm not yet. And my obligation is to accompany my friend to, to kind of companion species, as a companioning with each other through this time, which includes mental confusion a little bit for my dog (Donna Haraway: Story Telling for Earthly Survival 2017).

Here is a dog not only as a companion or a pet, but as an intimate friend for whom we are obligated to care in the cultivation of mutual "response-ability." This takes us further towards a different view of technics. Yet it turns out that not even this is quite enough. On another occasion, asked what she means by "humanimal," Haraway comments:

\begin{abstract}
I think of humanimal as a linguistic way of paying attention to the way human beings and other animals co-make each other in the making of history. And I think for example of the ways that any question in the world one really cares about these days, that matter, whether it's who is hungry, or what kind of carbon footprint is being made by food production, or what sorts of cruelty and brutality and caretaking are going on, among species and between species ... These are humanimal worlds ... you can't think these one species at a time. If you think about labour, or love, or play, I think you have to think multi species and I include technologies as species. Okay, so they're both living and nonliving and not ... I think people make a mistake with my work sometimes. I happen to love pets.... But they're not the definition of humanimal. They're one kind of thread within a very complex fabric (Human 2013, my emphasis).
\end{abstract}

The collectivities and socialities of the world come first (multispecies), and it is within this that we include "technologies as species." Technics here has to overcome many of its current modes in order to be equal to events "within a very complex fabric." This is not only a matter of biomimicry, of zoomorphism, or even of 'learning from nature.' As useful as all of these might be (or not), they very easily continue both a bifurcation of nature and an outmoded representationalism. Technics becomes rather a matter of an enhanced, complex, and immanent relationality, which technics does not dominate but in which whatever technics might become participates. This is crucial. It is very different from a technics that pushes everything into the uneven folding of too much of the world into a third media revolution, one in which humans dominate and even then, only the few. It would work instead towards active participation and response-ability towards the world as medium, as the "foster-mother of all becoming" or "the natural matrix of all things" (Plato, in Whitehead 1967, 134). 
This is also a return of play into technics, which enables abstraction to be lived rather than life suppressed in favor of abstract systems of control. Play breaks down the kinds of divisions so often preserved in interactive systems in favor of being able to inhabit the middle of the immanence of events of affecting and being affected. This does not, as Pavlov does, reduce difference. Rather such a situation, and whatever it is that technics is or becomes in such a situation, goes with the foster-mothering of the world. It creates a participatory zone of equal if different coming together. As Brian Massumi writes:

The mode of abstraction produced in play does not respect the law of the excluded middle. Its logic is that of mutual inclusion. Two different logics are packed into the situation. Both remain present in their difference and cross-participate in their performative zone of indiscernibility $(2014,6)$.

This is what it is to live. This is what it is to add content to activity, immanent to the event of activity. This is not so much even a matter of what technics, by itself, should become. It is rather a question of what technics should reshape itself to become-with.

There is also, of course, a great deal of reparative work to be done on behalf of all those called in from the wider world to a Pavlovian existence. This reparative work and adding content to activity are the two tasks of whatever it is that interactivity and interfaces will become.

\section{A MANIFESTO FOR THE FUTURE OF THAT-WHICH-WE- CURRENTLY-CALL-THE-INTERFACE}

It is perhaps best to finish with a little bit of a manifesto for the transformation of work with that-which-we-currently-call-interfaces, as this work heads towards 'media alive.' Work with that-which-we-currentlycall-the-interface might in the future:

1. Emphasize real mutual belonging and multiple modes of belonging within the world-at-large. In the process, it would undo hierarchical forms of organization.

2. Attend to the immanence, complexity, and dynamism of the communicative event, without reductionism.

3. Work with fields (variable complex ecologies of relation and difference [Brunner \& Fritsch 2011]) rather than simple lines and individual elements such as reflexes (innate or conditional). 
4. Attune to the shifting entanglements between external and internal, openings and closures, relationality and individuation.

5. Attend to the passive as power in its own right and thus think 'being affected,' which is present on all sides of any relation, with more subtlety and care.

6. Consolidate fields of entangled speculation and pragmatics that move away from extractive technics of organization.

7. Acknowledge the socio-ecological disaster of modernity (Moten 2015), including Pavlovism, and the current 'catastrophic multiplicity', which includes the problem of technics, as problematic for experiments in terms of feeling.

8. Attend to the dynamism and novelty of feeling that emerges in each and every event.

9. Challenge many mainstream understandings of technics. It may even be that when we fully consider the world as medium, we do not need the same concept of technics or at least of technology or even any such concepts at all. It would challenge the formation of technics within assemblages, agencements, and diagrammatics. ${ }^{14}$

10. Learn from aesthetics (patterns of relations) and from new forms of organization based on patterns of relation and not be determined by corporate, consumer, or old-style political needs.

11. Open to and learn from (and not just occasionally, if at all, cater to) diverse ways of perceiving, acting, thinking, and feeling.

12. Empower organizational multiplicities.

13. Attend to the need for de-automation as much as automation and develop a wariness concerning pre-automation.

14. Work/think/feel in terms of more than on/off states or responses.

15. Assume a rich variability, complexity, and mobility of the nervous system, extended across the three ecologies of mind, the social, and environment.

16. Abandon data as the given for predictable economies of the lifeless in favor of data as the potential for feeling, for affecting and being affected (Murphie 2019, 18ff).

17. Abandon the tinkering technics that flirts with inducing stress and instead create fields of relaxation, exploration, and belonging. 


\section{NOTES}

1. See Data for Black Lives at https://d4bl.org/.

2. The work referred to is here to give an idea of how wide ranging the fugitivity from control and move towards affect, very broadly conceived, are in both interaction and thinking about technics in general. It does not suggest that all this work agrees with the project in this chapter by any means. For example, Tallbear critiques the opposition between life and non-life as a way of relegating Indigenous peoples and ancestry to disappearance, at best to the service and appropriation of settler-colonists. She writes:

In order to sustain good relations among all the beings that inhabit these lands, we must undercut settler (property) relations. Instead of killing the Indian to save the man, we must turn the ontological table. The twenty-first-century mantra must be to kill the settler and save us all. Or as my Indigenous studies colleague and Lakota relative Nick Estes put it in an email to me, we must commit "settler ontocide." This does not, of course, mean literal killing. It means ridding ourselves of the category of the settler along with its discourse of white supremacy and assertions of an inherent right to these lands and waters.

So much of this has relevance within technical cultures. My tentative addition to this response is to work towards undoing the many bifurcations of nature, the hierarchies of the lifeless and alive at the basis of Western modern culture. The chapter here concerns general principles, not specific work in interactive design. However, the references to specific examples from a wide range of fields in these paragraphs hint at the rich possibilities for HCI and other fields engaging with the junction of design and technics when they venture out of the field as strictly constituted in the academy. This constitution could sometimes be seen as part of the problem (while acknowledging the many moves in different directions within it). Quite differently, there is the obvious need to take technics back from many industry, settler-colonialist formations.

3. Concrete suspended room, Pavlov's laboratory. Wellcome Collection, London (L0023485). https://wellcomecollection.org/works/kc22u2zc Attribution 4.0 International (CC BY 4.0).

4. Manometer at I. P. Pavlov's laboratory. Wellcome Collection, London (L0023484). https://wellcomecollection.org/works/rnkjnkn8 Attribution 4.0 International (CC BY 4.0).

5. From Lectures on conditioned reflexes/Ivan Petrovich Pavlov; translated and edited by W. Horsley Gantt; with the collaboration of G. Volborth; and an introduction by Walter B. Cannon. Wellcome Collection, London (M0014738). https://wellcomecollection.org/works/yzvjt8mu Attribution 4.0 International (CC BY 4.0).

6. See Natasha Dow Schüll's (2014) account of behaviorism in interaction design. 
7. This is something now applied, for example, to 'attention.'

8. This is a complex issue, and I intend to develop it in another context. However, in this regard, see Dupuy (2000), Dow Schüll (2014), Knox et al. (2019) on "Machine Behaviourism," or the recent documentary The Social Dilemma. Pavlov was actually interested primarily in the psyche's internal workings and data, not in external behaviors. Skinner, provoked by Whitehead no less, spent many years writing a book on language. Wiener and the entire cybernetics program heads in this direction.

9. "Thinking involves - though it is not reduced to-a basic and literal flow of proprioceptive intensities of the brain - the brain as world as medium feeling itself differentiating" (Murphie 2019, 33).

10. Some of Pavlov's associates extended his work into experiments on orphan children, who were conditioned by a machine that forced cookies into their mouths. Both children and dogs, which were strays, were made available for experimentation due to their powerless circumstances.

11. Via Duvernoy (2019).

12. For Goodman's own re-wilding involving technics, see pp. 176-231 of his Gathering Ecologies.

13. See Monica Gagliano (https://www.monicagagliano.com/), Gagliano (2018), Gibson (2015), and also Gibson and Brits (2018).

14. In my thinking here, which is slightly different from many other accounts, assemblages involve the at that time functional assemblage of material elements, active abstractions (ideas or, better, conceptual feelings), and the real relations, affects, tendencies, and potentials involved (in the Pavlov laboratories, for example). Agencements involve the way that aspects break off from specific assemblages and form new relations that enable a movement towards variable, multiple futures (so that Pavlov's laboratories, experiments, and concepts, for example, move towards a general, variable (Pavlovism'). Finally, diagrammatics is meant to describe ways of intervening in assemblages and agencements. Diagrammatics are technics within technics. They create new relations that move forces within assemblage and agencement. They can work immediately, to work within a particular situation. Or they can potentialize certain tendencies and relations, as these are directed toward the future. Diagrammatics also intervene between the movements of agencement and their crystallization into assemblages and vice versa - as a kind of variable, evolving 'how to.' They might include literal diagrams, models and procedures, maps, recipes, or even lists of all kinds. Yet diagrammatics might also involve a looser bringing together of abstractions (ideas, conceptual feelings, networks effects, patterns of relation), along with habits, intuitions, vague fringes of activity, and choreographies (purposeful or accidental). Design, including interaction design, obviously tends towards diagrammatics. 


\section{REFERENCES}

Amaro, R. (2020). Threshold Value. Architectures of Education. [online] e-flux. Available at: https://www.e-flux.com/architecture/education/322664/threshold-value/ [Accessed 13 October 2020].

Anderson, C. A. (1995). Process Philosophy and the New Thought Movement. [online] New Every Moment. Available at: https://neweverymoment.com/alan/Process\%20Philosophy\%20and\%20the\%20New\%20 Thought\%20Movement.htm [Accessed 15 October 2020].

Bateson, G. (1987). Steps to An Ecology of Mind: Collected Essays in Anthropology, Psychiatry, Evolution, and Epistemology. London: Jason Aronson Inc.

Benjamin. R. (2018). Black AfterLives Matter: Cultivating Kinfulness as Reproductive Justice. [online] Boston Review. Available at: http:// bostonreview.net/race/ruha-benjamin-black-afterlives-matter [Accessed 13 October 2020].

Benjamin, R. (2019). Race After Technology: Abolitionist Tools for the New Jim Code. London: Polity.

Bertelsen, L. (2012). FCJ-149 Affect and Care in Intimate Transactions. The Fibreculture Journal [online] 21. Available at: http://twentyone. fibreculturejournal.org/fcj-149-affect-and-care-in-intimate-transactions/ [Accessed 15 October 2020].

Boyle, C. (2018). Rhetoric as a Posthuman Practice. Columbus: Ohio State University Press.

Brunner, C. \& Fritsch, J. (2011). FCJ-124 Interactive Environments as Fields of Transduction. The Fibreculture Journal [online] 18, pp. 118-145. Available at: http://eighteen.fibrhttps://core.ac.uk/reader/186639337eculturejournal.org/2011/10/09/fcj-124-interactive-environments-as-fields-of-transduction/ [Accessed 15 October 2020].

Chandler, C. (2017). Animal-Assisted Therapy in Counseling. London: Taylor \& Francis.

Chun, W. (2011a). Programmed Visions: Software and Memory. Cambridge: MIT Press.

Chun, W. (2011b). Crisis, Crisis, Crisis, or Sovereignty and Networks. Theory, Culture \& Society 28 (6), pp. 91-112.

Costanza-Chock, S. (2020). Design Justice: Community-Led Practices to Build the Worlds We Need. Cambridge: MIT Press.

Cuppini, N. \& Frapporti, M. (2018). Logistics Genealogies: A Dialogue with Stefano Harney. Social Text 36 (3), pp. 95-110. 
Debaise, D. (2017). Nature as Event: The Lure of the Possible. Durham: Duke University Press.

Design Studio for Social Intervention, The (2020). Ideas Arrangements Effects: Systems Design and Social Justice. Brooklyn: Minor Compositions. Donahue, M. (2019). Flowers Can Hear Buzzing Bees - and It Makes Their Nectar Sweeter. [online] National Geographic. Available at: https:// www.nationalgeographic.com/science/2019/01/flowers-can-hearbees-and-make-their-nectar-sweeter/ [Accessed 24 June 2020].

Donna Haraway: Story Telling for Earthly Survival. (2017). [DVD] Brooklyn: Fabrizio Terranova.

Dourish, P. \& Cruz, E. G. (2018). Datafication and Data Fiction: Narrating Data and Narrating with Data. Big Data \& Society 5 (2), pp. 1-10.

Dow Schüll, N. (2014). Addiction by Design: Machine Gambling in Las Vegas. Princeton: Princeton University Press.

Dupuy, J-P. (2000). The Mechanization of the Mind: On the Origins of Cognitive Science. Princeton: Princeton University Press.

Durham Peters, J. (2015). The Marvelous Clouds: Toward a Philosophy of Elemental Media. Chicago: Chicago University Press.

Duvernoy, R. (2019). Deleuze, Whitehead, and the "Beautiful Soul." Deleuze and Guattari Studies 13 (2), pp. 163-185.

Edwards, P. (1996). The Closed World: Computers and the Politics of Discourse in Cold War America. Cambridge: MIT Press.

Ferster, B. (2014). Teaching Machines. Baltimore: JHU Press.

Foucault, M. (1980). Language, Counter-Memory, Practice: Selected Essays and Interviews. New York: Cornell University Press.

Fritsch, J. (2011). FCJ-137 Affective Experience in Interactive Environments. The Fibreculture Journal [online] 19. Available at: http://nineteen. fibreculturejournal.org/fcj-137-affective-experience-in-interactive-environments/ [Accessed 10 October 2020].

Fritsch, J., Loi, D. \& Light, A. (2019). Designing at the End of the World. DIS '19 Companion: Companion Publication of the Designing Interactive Systems Conference 2019, pp. 369-372.

Gagliano, M. (2018). Thus Spoke the Plant: A Remarkable Journey of Groundbreaking Scientific Discoveries and Personal Encounters with Plants. Berkeley, CA: North Atlantic Books.

Gerovitch, S. (2002). Love-Hate for Man-Machine Metaphors in Soviet Physiology: From Pavlov to "Physiological Cybernetics." Science in Context 15 (2), pp. 339-374. 
Gibson, P. (2015). Janet Laurence: The Pharmacy of Plants. Sydney: New South Books.

Gibson, P. \& Brits, B., eds. (2018). Covert Plants: Vegetal Consciousness and Agency in an Anthropocentric World. Goleta: Punctum.

Goodman, A. (2018). Gathering Ecologies: Thinking Beyond Interactivity. London: Open Humanities Press.

Goodman, A. (2019). Black Magic: Fragility, Flux and the Rewilding of Art. In: E. Manning, A. Munster and B. M. Stavning Thomsen, eds., Immediation I. London: Open Humanities Press, pp. 134-160.

Goodman, A. (2020). The Secret Life of Algorithms: Speculation on Queered Futures of Neurodiverse Analgorithmic Feeling and Consciousness. Transformations [online] 34, pp. 49-70. Available at: http:// www.transformationsjournal.org/wp-content/uploads/2020/05/ Trans34_04_goodman.pdf [Accessed 3 September 2020].

Guattari, F. (2000). The Three Ecologies. London: Athlone.

Gulson, K. \& Witzenberger, K. (2020). Repackaging Authority: Artificial Intelligence, Automated Governance and Education Trade Shows. Journal of Education Policy [online] early publication. Available at: https://doi.org/10.1080/0268The Secret Life of Algorithms: Speculation on Queered Futures of Neurodiverse 0939.2020.1785552 [Accessed 15 October 2020].

Gulson, K., Murphie, A. \& Witzenberger, K. (2021). Amazon Go for Education? Artificial Intelligence, Disruption and Intensification. In: C. Wyatt-Smith, B. Lingard and E. Heck, eds., Digital Disruption in Teaching and Testing: Assessments, Big Data, and the Transformation of Schooling. London: Routledge., pp. 90-106.

Haraway, D. \& Kenney, M. (2015). Anthropocene, Capitalocene, Chthulhucene: Donna Haraway in Conversation with Martha Kenney. In: H. Davis and E. Turpin, eds., Art in the Anthropocene: Encounters Among Aesthetics, Politics, Environments and Epistemologies. London: Open Humanities Press, pp. 229-244.

Haraway, D. (2017). Story Telling for Earthly Survival. FILM.

Harney, S. \& Moten, F. (2013). The Undercommons: Fugitive Planning and Black Study. Brooklyn: Minor Compositions.

Harries-Jones, P. (1995). A Recursive Vision: Ecological Understanding and Gregory Bateson. Toronto: Toronto University Press.

Harries-Jones, P. (2016). Upside-Down Gods: Gregory Bateson's World of Difference. New York: Fordham University Press. 
Heilig, L. (2019). Ways to Move, Ways to Map: Neurodiversity in Interaction Design. In: ATTW 2019 Conference. [online] Notes available at: bit. ly/The Secret Life of Algorithms: Speculation on Queered Futures of Neurodiverse 2VEE1jw [Accessed 13 October 2020].

Human (2013). Donna Haraway on the "Humanimal." [online] Available at: https://www.yThe Secret Life of Algorithms: Speculation on Queered Futures of Neurodiverse outube.com/watch?v=BUA_hRJU8J4 [Accessed 24 June 2020].

Kearsley, J. \& McPherson, E. (2019). "Whiteboard of Shame": Robo-debt Compliance Officers "Worked to Targets." [online] The Sydney Morning Herald. Available at: https://www.smh.The Secret Life of Algorithms: Speculation on Queered Futures of Neurodiverse com.au/politics/ federal/whiteboard-of-shame-robo-debt-compliance-officersworked-to-targets-20190809-p52foq.html [Accessed 24 June 2020]. Kelly, M. \& Garstand, M. (2013). On the Possible Detection of Lightning Storms by Elephants. Animals 3, pp. 349-355.

Kennerson, E. (2018). How Elephants Listen ... With Their Feet. [online] KQED Science. Available at: https://www.kqed.org/science/1926248/ how-elephants-listen-with-their-feet/ [Accessed 24 June 2020].

Kitchin, R. (2014). The Data Revolution: Big Data, Open Data, Data Infrastructures \& Their Consequences. London: Sage.

Knox, J., Williamson, B. \& Bayne, S. (2020). Machine Behaviourism: Future Visions of 'Learnification' and 'Datafication' Across Humans and Digital Technologies. Learning, Media and Technology 45 (1), pp. 31-45. Kukutai, T. \& Taylor, J. (2016). Indigenous Data Sovereignty: Toward An Agenda. Canberra: ANU Press.

Lotti, L. (2015). "Making Sense of Power": Repurposing Gilbert Simondon's Philosophy of Individuation for a Mechanist Approach to Capitalism (by way of François Laruelle). Platform: Journal of Media and Communication 6, pp. 22-33.

Lotti, L. (2018). Cryptoeconomics And/As Artistic Practice: Sketches for New Design Imaginaries. Schloss, [online] Issue No 0-Digital Culture, Theory \& Art, October 1. Available at: https://schloss-post.com/cryptoeconomics-artistic-practice/ [Accessed 17 October 2020].

Lotti, L. (2019). The Art of Tokenization: Blockchain Affordances and the Invention of Future Milieus. media theory [online] 3 (1), pp. 287-320. Available at: http://journalcontent.mediatheoryjournal.org/index. $\mathrm{php} / \mathrm{mt} /$ article/view/90 [Accessed 16 October 2020]. 
MacKenzie, A. \& Munster, A. (2019). Platform Seeing: Image Ensembles and Their Invisualities. Theory, Culture \& Society 36 (5), pp. 3-22.

Manning, E. (2020). For a Pragmatics of the Useless. Durham: Duke University Press.

Manning, E., Munster, A. and Stavning Thomsen, B. M. (2019). Immediation I and II. London: Open Humanities Press.

Massumi, B. (2011). Semblance and Event: Activist Philosophy and the Occurrent Arts. Cambridge: MIT Press.

Massumi, B. (2014). What Animals Teach Us about Politics. Durham: Duke University Press.

Massumi, B. (2015). Ontopower: War, Powers, and the State of Perception. Durham: Duke University Press.

Marx, K. \& Engels, F. (1977). The Communist Manifesto. Moscow: Progress Publishers.

Mattern, S. (2018). The Ever-Expanding Field of Media Studies: Ideas for Understanding the Mediated World. [online] Public Seminar. Available at: http://www.publicseminar.org/2018/03/the-ever-expanding-field-of-media-studies/ [Accessed 24 June 2020].

McCulloch, W. \& Pitts, W. (1943). A Logical Calculus of the Ideas Immanent in Nervous Activity. The Bulletin of Mathematical Biophysics 5 (4), pp. 115-133.

Moten, F. (2015). Blackness and Poetry. [online] Evening Will Come. Available at: https://arcade.stanford.edu/content/blackness-and-poetry-0 [Accessed 24 June 2020].

Murphie, A. (2014). Auditland. PORTAL: Journal of Multidisciplinary International Studies [online] 11(2). Available at: https://epress.lib.uts.edu. au/journals/index.php/portal/article/view/3407/4581 [Accessed 11 October 2020].

Murphie, A. (2018). On Being Affected: Feeling in the Folding of Multiple Catastrophes. Cultural Studies 32(1) pp. 18-42.

Murphie, A. (2019). The World As Medium: A Whiteheadian Media Philosophy. In: E. Manning, A. Munster, and B. M. Stavning Thomsen, eds., Immediation I. London: Open Humanities Press, pp. 16-48.

O'Connell-Rodwell, C. (2007). Keeping an 'Ear' to the Ground: Seismic Communication in Elephants. Physiology 22, pp. 287-294.

Parisi, L. (2013). Contagious Architecture: Computation, Aesthetics, and Space. Cambridge: MIT Press. 
Pascoe, B. (2014). Dark Emu: Black Seeds: Agriculture or Accident. Broome: Magabala.

Penn, J., McNealy, J. \& Running Wolf, M. (2020). On Data Ecologies and Sacred Data | $\operatorname{CogX} 2020$. [online] Available at: https://youtu.be/ gL-8TUoCqXE [Accessed 13 October 2020].

Plumb, L. (2016). Re-Orientations Rather Than Reframing: A Few Thoughts On Designing With The Digital. In: A. Murphie, ed., The Go-To How-To Book of Anarchiving. Montréal: SenseLab, pp. 69-71.

Rogers, Y. \& Marshall, P. (2017). Research in the Wild. London: San Rafael, California: Morgan \& Claypool.

Running Wolf, C. \& Running Wolf, M. (2017). Reigniting the Many Voices of a Communal Bison Hunt in Virtual Reality. In: 5th International Conference on Language Documentation and Conservation (ICLDC). University of Hawai'i at Mānoa [online] Available at: http://hdl.handle. net/10125/42023 [Accessed 13 October 2020].

Running Wolf, C. \& Running Wolf, M. (2019). Sacred Waveforms: An Indigenous Perspective on the Ethics of Collecting and Usage of Spiritual Data for Machine Learning. [online] Available at: https://slideslive. com/38923838/invited-talk-track-3-sacred-waveforms-an-indigenous-perspective-on-the-ethics-of-collecting-and-usage-ofspiritual-data-for-machine-learning [Accessed 13 October 2020].

Scholz, T. \& Schneider, N. (2017). Ours to Hack and to Own: The Rise of Platform Cooperativism, A New Vision for the Future of Work. New York: OR Books.

Serres, M. (2019). Hominescence. London: Bloomsbury.

Skinner, B. F. (1960). Pigeons in a Pelican. American Psychologist 15 (1), pp. $28-37$.

Smith, O. B. (2010). The Social Self of Whitehead's Organic Philosophy. European Journal of Pragmatism and American Philosophy [online] II(1). Available at: https://journals.openedition.org/ejpap/935 [Accessed 15 October 2020].

Tallbear, K. (2019). Caretaking Relations, Not American Dreaming. Kalfou: A Journal of Comparative and Relational Ethnic Studies 6 (1), pp. 24-41. Todes, D. (2014). Ivan Pavlov: A Russian Life in Science. Oxford: Oxford University Press.

Wakefield, S. (2020). Anthropocene Back Loop: Experimentation in Unsafe Operating Space. London: Open Humanities Press. 
Watters, A. (forthcoming). Teaching Machines. Cambridge: MIT Press. Whitehead, A. (1926). Religion in the Making. New York: Macmillan. Whitehead, A. (1967). Adventures in Ideas. New York: Simon and Schuster. Whitehead, A. (1968). Modes of Thought. New York: The Free Press. Whitehead, A. (1978). Process and Reality. New York: The Free Press. Whitehead, A. (2004). The Concept of Nature. New York: Prometheus Books. Wiener, N. (1948). Cybernetics: Or Control and Communication in the Animal and the Machine. Cambridge: MIT Press.

Zwart, H. (2018). Conditioned Reflexes and the Symbolic Order: A Lacanian Assessment of Pavlov's Experimental Practice. Vestigia: The Journal of the International Network of Psychotherapeutic Practice 2 (1), pp. 58-96. 